\title{
Akademik Yayınlar Işs̆ğında Toplum 5.0 Kavramına İlişkin Bir Değerlendirme ${ }^{1}$

Nisa AKIN $^{2}$
Evrim MAYATÜRK AKYOL
Olca SÜRGEVIL DALKILIÇ

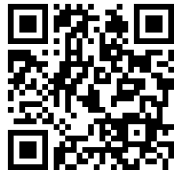

\begin{tabular}{ccc}
\hline Geliş Tarihi/ Received & Kabul Tarihi/ Accepted & Yayın Tarihi/ Published \\
$09 / 09 / 2020$ & $08 / 02 / 2021$ & $15 / 04 / 2021$ \\
\hline Citation/Atıf: Akın, N., Mayatürk Akyol, E. ve Sürgevil Dalkılıç, O. (2021), Akademik Yayınlar \\
Işı̆̆ında Toplum 5.0 Kavramına İlişkin Bir Değerlendirme, Atatürk Üniversitesi İktisadi ve İdari \\
Bilimler Dergisi, 35(2): Sayfa: $577-593$, https://doi.org/10.16951/atauniiibd.792750 \\
\hline
\end{tabular}

Öz: Bu çalışmada, endüstri 4.0 bağlamında tartışılan yeni teknolojilerin insanların günlük yaşamları ve toplum ile bütünleştirilmesini hedefleyen toplum 5.0'ın literatürde nasıl ele alındığını değerlendirmek amaçlanmaktadır. Bu doğrultuda betimsel bir araştırma yürütülmüsş, başlığında ya da anahtar kelimelerinde "toplum 5.0" ve "society 5.0" geçen 27 makale söz konusu araștırmanın örneklemini oluşturmuştur. Analiz sonucunda en fazla makalenin 2019 yılında yayınlandığı, çalışmaları yürüten akademisyenlerin kavramın doğduğu Japonya'da yoğunlaştığı, makalelerin çoğunun literatür incelemesi șeklinde tasarlandığı, çalışmaların odaklandığı konuların ise toplum, çalışma hayatı ve teknoloji şeklinde sınıflanabildiği saptanmıştır. Bununla birlikte, konuya ilişkin derin bir kavramsal tartışmaya hali hazırda ihtiyaç duyulduğu söylenebilmektedir.

Anahtar Kelimeler: Toplum 5.0, Akıllı Toplum, Süper Akıllı Toplum, Endüstri 4.0

An Evaluation of the Concept of Society 5.0 in the Light of Academic Publications

Abstract: In this study, it is aimed to evaluate how society 5.0, which aims to integrate new technologies discussed in the context of industry 4.0 with people's daily lives and society, is handled in the literature. Accordingly, a descriptive research was carried out, and 27 articles that included "society 5.0" and "toplum 5.0" in the title or in the keywords, constituted the sample of the study in question. As a result of the analysis, it was determined that the most articles were published in 2019, the academicians who conducted the studies concentrated in Japan, where the concept was born, most of the articles were designed as a literature review, and the subjects focused on the studies could be classified as society, working life and technology. However, it can be said that a deep conceptual discussion on the subject is currently needed.

Keywords: Society 5.0, Smart Society, Super Smart Society, Industry 4.0

JEL Codes: M1, O33, O35

${ }^{1}$ Bu çalı̧̧ma, 21-22 Kasım 2019 tarihlerinde düzenlenen IV. Yönetim ve Organizasyon Çalıştayı'nda sunulan "Akademik Yayınlar Işı̆ğında Toplum 5.0 Kavramına İlişkin Bir Değerlendirme" başlıklı yayınlanmamış bildirinin genişletilmiş halidir.

${ }^{2} \mathrm{Dr}$. Ö̆gr. Üyesi, İzmir Kâtip Çelebi Üniversitesi, İktisadi ve İdari Bilimler Fakültesi, İşletme Bölümü,nisa.akin@ikcu.edu.tr, https://orcid.org/0000-0002-5849-1629

${ }^{3}$ Doç. Dr., İzmir Kâtip Çelebi Üniversitesi, İktisadi ve İdari Bilimler Fakültesi, İşletme Bölümü, evrim.akyol@ikcu.edu.tr,https://orcid.org/0000-0001-9583-1912

${ }^{4}$ Doç. Dr., Dokuz Eylül Üniversitesi İktisadi ve İdari Bilimler Fakültesi İşletme Bölümü, olca.surgevil@deu.edu.tr, https://orcid.org/0000-0002-7667-8104 
Akademik Yayınlar Işı̆̆ında Toplum 5.0 Kavramına İlişkin Bir Değerlendirme

\section{EXTENDED SUMMARY}

\section{Research Problem}

The main purpose of this study is to evaluate how "society 5.0" concept is handled in the current academic literature and make inferences about the theoretical infrastructure of the concept. The aim of the study is also to analyze the concept of "society 5.0" in terms of the years of academic publications, their scope, related topics and country contexts.

\section{Research Questions}

The research questions were set according to this objective:

a) How can the concept of Society 5.0 be explained?

b) What is the theoretical infrastructure of the concept of Society 5.0?

c) How do the scope and content of academic publications related to Society 5.0 develop or change over the years?

\section{Background}

The concept of Society 5.0 emerged in 2015 in Japan. Society 5.0, described as smart society or super smart society, was introduced by Japanese Prime Minister Shinzo Abe. Introducing the philosophy of society 5.0, Shinzo Abe stated that technology is not a threat to societies but a supporter for societies, and also Society 5.0 is an understanding which is led by science and technology, and transforms with the opportunities offered by industry 4.0 and digitalization. Society 5.0, which has development goals such as e-learning systems, smart cities, and innovative ecosystem, aims to overcome social problems and improve people's quality of life by integrating the digital environment and the physical environment. Accordingly, in this study, a descriptive research was carried out to evaluate the academic studies on the concept of society 5.0 to understand it more.

\section{Methodology}

In this study, in which a descriptive research was conducted, the studies in the academic literature on the concept of society 5.0 were taken into consideration. In line with the design of the research, academic articles in English and Turkish languages were searched, and the concept of "society 5.0" was scanned in titles and keywords in databases of Google Scholar and İzmir Kâtip Çelebi University. Among the English publications, we meet 17 academic articles that have the concept of society 5.0 in the title and 5 academic articles that have the concept of society 5.0 in the keywords; and among the Turkish publications we meet 5 academic articles that have the concept of society 5.0 in the keywords.

\section{Results and Conclusions}

Considering the distribution of studies by years, 3 studies were conducted in 2017, 10 studies in 2018 and 14 studies in 2019; 64\% of these studies are carried out by universities and $36 \%$ are carried out by research centers, laboratories, science and technology centers. It is also seen that the number of researchers working in the Society 5.0 area is from Japan (15 people). When all 
of the studies are evaluated, it is seen that 16 studies are literature reviews and 11 are research articles. When studies are considered in the context of their subjects; 10 studies addressed social content issues such as individual technology compliance, security and welfare, environmental sustainability, technology dependence, religion and ethics, generational differences, smart cities; 8 studies deal with issues related to working life such as management phenomenon (human resources management, teamwork, strategic planning), tourism, marketing and costing; 9 of them appear to focus on technology and innovation themes such as digitalization, sustainability and energy, science technology and innovation ecosystem. As a result, it is seen that in the handling of the subject of Society 5.0, there is a need for a deep academic perspective, researches from different contexts of the countries, and the interest of researchers working in the field of social sciences.

\section{Giriş}

İnsanlık tarihine baktığımızda, avcı toplum (toplum 1.0), tarım toplumu (toplum 2.0), endüstri toplumu (toplum 3.0), bilgi toplumu (toplum 4.0) ve günümüzde de bilgi toplumu üzerine inşa edilen toplum 5.0 başka bir deyişle ak1llı toplum (süper ak1llı toplum)'dan bahsedilmektedir (Fukuyama, 2018). Söz konusu tarihsel gelişim sürecinin, internetin varlığı ile birlikte hızlı bir gelişim gösterdiği soylenebilmektedir. Diğer bir deyişle, avc1 toplumu iki yüz bin yı1, tarım toplumu on bin yıl, endüstri toplumu iki yüz yıl üzerinde varlığını sürdürmüşken, dijital dönemde ise değişimler, on yıllık aralıklar ile gerçekleşmektedir (Saracel\&Aksoy, 2020). İnsanı teknolojinin merkezine yerleştirerek, başka bir deyişle teknolojiyi toplumun avantajına kullanarak yeni değerler yaratmayı amaçlayan toplum 5.0, teknolojik gelişmelerin toplumla bütünleşmesine odaklanmıştır ve insan odaklı bir toplum anlayışı sunmaktadır (Okan Gökten, 2018). Toplum 5.0 kavramı, endüstri 4.0 ile dönüşen ancak endüstri 4.0'a uyum sağlamak için yapılması gerekenlere proaktif yaklaşarak önde olmayı niteleyen bir bakış açısıyla da değerlendirilmektedir.

Toplum 5.0, endüstri 4.0'ın kazanımlarını insanların günlük yaşantılarına daha derinden bütünleştirebilmeleri ilkesini benimsemektedir (Gladden, 2019). Ak1llı teknolojiler, nesnelerin interneti, sanal gerçeklik, yapay zeka, nano teknoloji, giyilebilir teknoloji, arttırılmış gerçeklik, akıllı robotlar, büyük veri gibi yeni teknolojilerin yön verdiği endüstri 4.0; çalışma ortamlarını, iş görme şekillerini, iletişim yaklaşımlarını başka bir deyişle tüm toplumu farklı yön ve boyutlarda değiştirmektedir (Bahar\&Topsakal, 2019; Topsakal vd., 2018). Toplum 5.0'ın temel amaçları arasında; insanların rahat ve konforlu hissettiği ve aktif katılım gösterdiği bir toplum; kişisel farklılıklardan bağımsız herkesin ihtiyaçlarının uygun ürün ve hizmetlerle karşılandığı bir sistem; herkes için eşitlik ve aynı zamanda bireylerin kendi potansiyellerini fark etmelerinin desteklenmesi yer almaktadır (Fukuyama, 2018).

Toplum 5.0'ın mevcut akademik yazında nasıl ele alındığını değerlendirmek ve teorik alt yapısına ilişkin çıkarımlarda bulunabilmek amacıyla 
gerçekleştirilen bu çalışmada, yerli ve yabancı yazın incelenmiş ve ilgili akademik yayınların yılları, kapsamları ve ele aldıkları ilişkili konular ve ülke bağlamları hakkında fikir sahibi olmak amaçlanmıştır.

Çalışmanın kavramsal çerçeve bölümüyle incelenen makalelerde görülen kavramsal tartışma eksikliğinin giderilmesi, konunun birlikte ele alındığı değişkenlerin tespiti ile yoğunlaşılan ve göz ardı edilen hususların saptanması, başlıkta toplum 5.0 kavramını kullanarak başta yerli yazın açısından alan taraması kolaylığının sağlanması ve ileride konuyu ele alacak araştırmacılara söz konusu kavramla ilgili bir bakış açısı sunulması noktalarında literatüre katkı sağlaması beklenmektedir.

\section{Kavramsal Çerçeve}

Toplum 5.0 kavramı, 2015 yılında Japonya'da stratejik bir siyasi inisiyatifle ortaya çıkmış (Wang vd., 2018); 2016 yılında Japon hükümeti "Beşinci Bilim ve Teknoloji Planı"nda kavram olarak kullanılmış ve aynı zamanda "2017 yıl1 Gelecek Stratejisine Yatırım: Toplum 5.0 Reformu"nun temel bir parçası yapılmıştır (Fukuyama, 2018). "Akıllı toplum" hatta "süper ak1llı toplum" olarak nitelenen toplum 5.0; 2017 yılında dünyanın en büyük bilişim-teknoloji fuarlarından biri olan CEBIT'de (Hannover, Almanya) Japonya başbakanı Shinzo Abe tarafından tanıtılmıştır. Toplum 5.0 felsefesini tanıtan Shinzo Abe, teknolojinin toplumlar için tehdit değil yardımcı olduğunu belirtmiş ve toplum 5.0'ın, bilim ve teknolojinin öncülügünde, endüstri 4.0 ve dijitalleşmenin sunduğu imkanlarla dönüşen bir toplum anlayışı olduğuna işaret etmiştir.

Endüstri 4.0, 2011 yılında Almanya' da ortaya atılmış ve işletme çevresinin dijitalleşmesini sağlayan birbiriyle bağlantılı tüm teknolojileri temsil etmektedir. Genellikle dört temel boyutta (Siber fiziksel sistemler, nesnelerin interneti, hizmetlerin interneti ve akıllı fabrikalar) ve altı temel teknoloji (nesnelerin endüstriyel interneti ve siber fiziksel sistemler, eklemeli üretim-3D yazıcılar, büyük veri, yapay zekâ, akıllı robotlar, sanal gerçeklik) bağlamında ele alınmaktadır (Akt: Skobelev\&Borovik, 2017). Endüstri 4.0'la yaşamak için; toplumların eğitilmesi (yaratıcı eğitimler ve yaşam boyu eğitim anlayışıyla); yapay zeka ve endüstri 4.0'ın sunduklarıyla ilgili insanların endişelerinin giderilmesi ve yapay zeka-insan işbirliklerinin artırılması gereklidir (Karabacak\&Sezgin, 2018).

Endüstri 4.0'ın üzerine inşa edilen toplum 5.0, Japonların gelişim stratejisi olmakla birlikte, sadece Japonya'yla sınırlı değildir ve bu yaklaşımın dünyadaki toplumsal sorunlarla baş etmeyi desteklemesi beklenmektedir. Günümüzde dünya çapında endüstri ve sosyal yaşamın nasıl bütünleştirilebileceği tartışılmaktadır (Fukuyama, 2018). Toplum 5.0'1n gelişim hedeflerine bakıldığında; kadınların güçlendirilmesi, e-öğrenme sistemleri, erken uyarı sistemleri, akıllı tarım ve akıllı gıda, akıllı şehirler, yenilikçi ekosistem gibi alanlar olduğu görülmektedir (Shiroishi vd., 2018; Fukuyama, 2018). Özetle Japonya'dan yükselen toplum 5.0 ile ekonomik ve toplumsal açıdan insanlara 
yüksek yaşam kalitesi sunan, insan merkezli bir toplum yapısının inşa edilmesi hedeflenmektedir (Akt. Karabacak\&Sezgin, 2018).

Toplum 5.0 paradigması, yapay zekanın insanların yaşamlarına girmesi ve insan kapasitesini artırmak ve insanı "Evrenin Merkezi”ne tekrar yerleştirmek için insanlarla yapay zekanın işbirliği yapmaları şeklinde de tanımlanmaktadır (Skobelev\&Borovik, 2017). Toplum 5.0 paradigmasının en önemli yönü; ırk, din, dil, cinsiyet vb. ayrımlar olmaksızın herkes için konforlu bir toplum yaratmanın gerekliliğine yaptığı vurgudur. Bu paradigma, teknolojiler aracıllğıyla fiziksel ve sosyal bariyerlerin ortadan kalkabileceğini, sosyal yaşamın aktif parçası olmak isteyen bireyler için eşit fırsatlar yaratılabileceğini ve aynı zamanda kişilerin öz farkındalık sahibi olmalarının desteklenebileceği fikirlerini içermektedir. Toplum 5.0 bakış açısına göre ancak bu yolla sosyal ve ekonomik açıdan tutarlı bir gelişim sağlanabilir (Bryndin, 2018).

Toplum 5.0'ın inovasyonları kontrol ederek insanların iyiliğine hizmet amacı taşıdığ söylenebilir. Toplum 5.0, konuyu sadece endüstri ile sınırlamayıp toplumsal bütünlügü de dikkate almaktadır (Riminucci, 2018). Toplum 5.0 anlayışı, işletmeleri toplum odaklı teknolojiler yaratma konusunda motive etmekte ve böylece işletmeler insanların yaşamlarını geliştirmeye katkı sağlayabilmektedir. Bu doğrultuda işletmelere, insanların yaşam kalitelerini yükseltmek ve toplumsal fayda yaratmak amacıyla üniversitelerle işbirliği halinde olmaları ve daha akıllı sistemlerle çalışacak yeni neslin eğitimine dâhil olma yolunu seçmeleri önerilmektedir (Bryndin, 2018). Nitekim Japonya' daki kurumlar, üniversiteler ve işletmeler aktif bir şekilde Toplum 5.0 paradigmasının gelişimi ve uygulanması konusunda işbirliği yapmaktadır (Akt: Gladden, 2019).

Eski bilgi toplumundaki yaygın uygulama ağlar aracılığıyla bilginin toplanmas1 ve insanlar tarafindan analiz edilmesi iken, toplum 5.0 döneminde bilgi insanın yanı sıra makineler, robotlar, bilgisayarlar ve nesneler tarafindan da üretilmektedir (Şen, 2019). Ayrıca Toplum 5.0 çağında gerçek fiziksel ortamlardan sensörlerle alınan bilgiler, sanal ortamda toplanmakta ve yapay zeka ile analiz edilmekte ve bu analiz sonuçları insanların yaşadığı fiziksel dünyaya farklı şekillerde geri dönmektedir. Toplum $5.0^{\prime}$ da insanlar, nesneler ve sistemlerin hepsi sanal ortamda birbiriyle ilişkilendirilmekte ve sonuçlar fiziksel ortama aktarılmaktadır. Bu sürecin hem endüstriye hem de topluma yeni değerler getirmesi beklenmektedir (Önday, 2019).

Toplum 5.0, insanların yaşamlarını sürdürebilmek için ihtiyaç duydukları minimum ürün ve hizmetleri sağlamak değil aynı zamanda insanların hayatlarını daha eğlenceli ve anlamlı yapanı aramak, dolayısıyla insan-teknoloji etkileşimi ile "daha sürdürülebilir, yaşayan, insan odaklı bir dünya"ya sahip olmayı amaçlamakta (Akt: Gladden, 2019) ve bu doğrultuda teknolojinin yoksulluğu önlemeye, evreni ve ekosistemi korumaya destek olabileceğini savunmaktadır (Shiroishi vd., 2018). Nitekim "insanlarla nesneler" ve "gerçekle sanal" arasındaki bağı etkili bir şekilde kurmak, sürdürülebilir sağlıklı ekonomik gelişme için de gerekli görülmektedir (Shiroishi vd., 2018). Bu doğrultuda 
toplum 5.0'in temel amaçlarından birinin de "sanal ortamla gerçek yaşamı yüksek derecede birleştirmek" olduğunu belirtmek mümkündür (Gladden, 2019).

Özetle toplum 5.0'1n ana fikri, dijital çevre ile fiziksel çevreyi bütünleştirerek sosyal problemleri aşmak ve bunun sonucu olarak da insanların yaşam kalitesini geliştirmektir. Bu paradigma hümanizmadan beslense de, bazı sorunlu yanlar ve riskler barındırdığı da belirtilmektedir (Nurillin, 2019). Örneğin internet, online video oyunları, akıllı telefon bağımlılıkları gibi yeni bağımlılık türlerinin ortaya çıkması (Gladden, 2019; Takahashi, 2018); bilgi güvenliği ve kişisel mahremiyetin korunmasındaki zorluklar, sahte haberlerin hızlı yayılımı bu risklerin başında yer almaktadır (Shiroishi vd., 2019). Aynı zamanda farklı ortamlarda endüstri 4.0 ve beraberinde toplum 5.0 ile işsizlik oranlarının yükseleceği de tartışılmaktadır. Fakat farklı çevreler tarafından yeni iş ve meslek alanlarının doğacağı ya da insanlarla robotların işbirliğinin en üst seviyede olduğu bu toplum yapısında, insanların kontrol ve takip işlerinde yer almaya devam edecekleri de belirtilmektedir (Okan Gökten, 2018).

\section{Tasarım ve Yöntem}

Çalışma kapsamında, toplum 5.0 kavramına ilişkin mevcut akademik değerlendirmeleri belirlemeye yönelik betimsel bir araştırma yürütülmüştür. Kavrama ilişkin akademik yazında bulunan ve araştırma evrenini oluşturan kitap, kitap bölümü, makale, bildiri, araştırma raporu ve tezlerin tamamına erişmenin çeşitli güçlükleri mevcuttur. Konunun henüz yeni ve sınırlı çalışılması sebebiyle, teorik altyapısının kavramsal çelişkiler içermesi bu güçlüklerin başında gelmektedir. Bu nedenle, toplum 5.0 yazını hakkında mevcut durumu etraflıca tanımlamak ve belirli unsurlara göre mevcut ve olası ilişkileri ortaya çıkarmak için yürütülen bu çalışmada, araştırma evrenini temsil etmesi açısından yazında yer alan akademik makaleler ele alınmıştır.

Araştırmanın tasarımı doğrultusunda, başlığında ve anahtar kelimelerinde "society 5.0" ve "toplum 5.0" geçen akademik makaleler Google Scholar ve İzmir Kâtip Çelebi Üniversitesi veri tabanlarında taranmıştır. Araştırmanın kapsamı da, konu ile ilgili yayımlanan yerli (Türkçe dilinde) ve yabancı (İngilizce dilinde) yazındaki toplam 27 akademik makaleden oluşmaktadır. Erişilen yayınlar içerisinde başlı̆̆ında "society 5.0" geçen 17 makale ile anahtar kelimelerinde "society 5.0" geçen 5 adet makale mevcuttur. Benzer tarama anahtar kelimelerinde ve başlığında "toplum 5.0" geçen yayınlar için gerçekleştirildiğinde ise, başlığında "toplum 5.0" geçen herhangi bir akademik makaleye erişilemezken, anahtar kelimelerinde "toplum 5.0" geçen 5 adet makaleye ulaşılmıştır. Söz konusu makalelerin tam metinleri ve künyeleri incelenerek veri toplama işlemi gerçekleştirilmiştir.

Araştırma kapsamında yer alan akademik makalelere ilişkin veriler derlenirken, öncelikle yayınlar yıllarına, araştırmacılarına ve yayınlandıkları dergilere göre tasnif edilmiştir. Tablo 2'de de görüldüğü üzere, toplum 5.0 yazınında yer alan akademik makaleler için bir dizin oluşturulmuştur. Her bir 
yayın, sayı verilerek kodlanmıştır. Dizinde yer alan yayınlar daha sonra araştırmacı sayısına, yazarlarının ülkelerine ve bağlı bulundukları kurumlara göre değerlendirilmiştir. Elde edilen akademik yayınlar, kapsam ve detaylarına göre de incelenmiştir. Makale türüne göre, literatür incelemesi (review) ve araştırma makalesi (research) şeklinde değerlendirilen çalışmalar ayrıca, konularına ve araştırmanın kapsamında yer alan ülkelere göre de sınıflandırılmıştır.

\section{Bulgular ve Tartışma}

Araştırma kapsamında yer alan akademik makaleler incelendiğinde, toplum 5.0 kavramının ilk olarak 2017 yılında çalışıldığı görülmektedir. Türkçe dilinde yayımlanan akademik makaleler için başlangıç yılı ise 2018 olarak tespit edilmiştir. Elde edilen 27 akademik makale, çalışmaların yılları bağlamında değerlendirildiğinde, 2017 yılında 3, 2018 yılında 10 ve 2019 yılında 14 yayına erişilmektedir (Grafik 1).

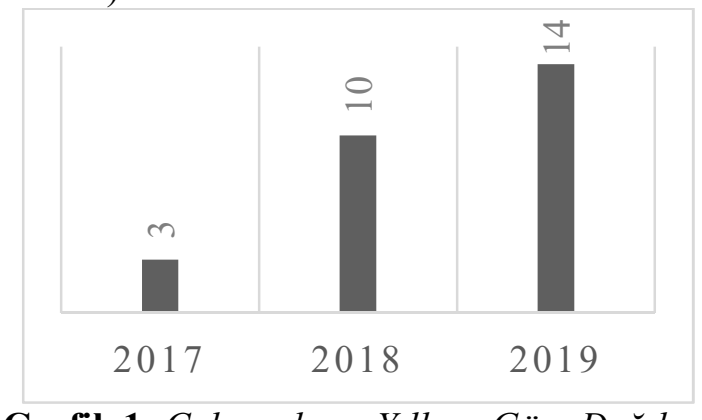

Grafik 1: Çalışmaların Yıllara Göre Dağılımı

Araştırmaya konu olan 27 yayının 5'i Türkçe dilinde yazılmış olup, Türk akademisyenler tarafından çalışılmıştır. İngilizce dilinde yayımlanan 22 yayın arasından 1'i ise Türk bir akademisyen tarafından yazılmıştır. Bununla birlikte, çalışmaları yürüten akademisyenlerin Japonya'da yoğunlaştığı görülmektedir (Tablo 1). Kurumsal çeşitliliğin en yüksek oranda görüldüğü ülke ise Türkiye'dir. Bunu sırasıyla Japonya ve Rusya izlemektedir. Araştırmacıların bulundukları kurumlar incelendiğinde, 23'ü üniversite ve 13'ü araştırma merkezi, devlet kurumu, laboratuvar ve bilim-teknoloji merkezi olmak üzere toplam 36 kurum mevcuttur. Araştırmacı sayıları değerlendirildiğinde, konunun sıklıkla Japonya'daki araştırmacılarca tartışıldığı görülmektedir. Bununla birlikte, Türkiye'de ve Rusya'da da konu ile ilgili çalışan akademisyenlerin yoğunlukta olduğu söylenebilmektedir. 
Akademik Yayınlar Işı̆̆ında Toplum 5.0 Kavramına İlişkin Bir Değerlendirme

Tablo 1: Çalışmaların Araştırmacı Sayısına, Araştırmacıların Ülkelerine ve Kurumlarına Göre Dağılımı

\begin{tabular}{|c|c|c|}
\hline Ülke & Kurum & $\begin{array}{l}\text { Araştırmacı } \\
\text { Sayısı }\end{array}$ \\
\hline \multirow{8}{*}{ Japonya } & Hitachi Ltd. & 4 \\
\hline & $\begin{array}{l}\text { National Institute of Advanced Industrial Science and } \\
\text { Technology }\end{array}$ & 1 \\
\hline & Japan Science and Technology Agency & 1 \\
\hline & Kitami Institute of Technology & 4 \\
\hline & Hokkaido University & 2 \\
\hline & Kobe University & 1 \\
\hline & $\begin{array}{l}\text { Mitsubishi Electric Cooperation, Advanced Technology } \\
\text { R\&D Center }\end{array}$ & 1 \\
\hline & Kyushu University & 1 \\
\hline Litvanya & Kaunas University of Technology & 3 \\
\hline \multirow{2}{*}{ Portekiz } & University of the Azores & 1 \\
\hline & Interdisciplinary Centre of Social Sciences & 1 \\
\hline \multirow{4}{*}{ Endonezya } & STMIK Handayani Makassar & 1 \\
\hline & STIE AMKOP Makassar & 1 \\
\hline & STIE Nobel Indonesia & 2 \\
\hline & Universitas Muslim Indonesia & 2 \\
\hline \multirow{9}{*}{ Türkiye } & Yeditepe University & 1 \\
\hline & Ministry of Commerce & 1 \\
\hline & $\begin{array}{l}\text { Adana Alparslan Türkeş Science and Technology } \\
\text { University }\end{array}$ & 1 \\
\hline & Cappadocia University & 1 \\
\hline & Akdeniz University & 2 \\
\hline & TOBB University of Economics and Technology & 1 \\
\hline & Osmaniye Korkut Ata University & 1 \\
\hline & Ankara Hacı Bayram Veli University & 1 \\
\hline & Celex Travel & 1 \\
\hline \multirow{5}{*}{ Rusya } & $\begin{array}{l}\text { National Research Mordovian State University N. P. } \\
\text { Ogaryov }\end{array}$ & 3 \\
\hline & Financial University & 1 \\
\hline & Kazan Federal University & 1 \\
\hline & $\begin{array}{l}\text { Research Centre "Nature Informatic", Tecnological } \\
\text { Platform Future Medicine }\end{array}$ & 1 \\
\hline & $\begin{array}{l}\text { Institute for the Control of Complex Systems of Russian } \\
\text { Academy of Sciences }\end{array}$ & 2 \\
\hline İngiltere & Anglia Ruskin University & 1 \\
\hline Çekya & Brno University of Technology & 2 \\
\hline \multirow{2}{*}{ Hindistan } & Amity University & 1 \\
\hline & Freelancer & 1 \\
\hline İtalya & ESRI Italia & 1 \\
\hline Almanya & NEC Laboratories Europe GmbH & 2 \\
\hline Malezya & International Islamic University Malaysia & 1 \\
\hline
\end{tabular}

Araştırma kapsamında değerlendirilen akademik makalelerin türlerine ilişkin değerlendirme yapıldığında (Tablo 2), 11 yayının araştırma, 16 yayının da 
literatür incelemesi şeklinde tasarlandığ literatür incelemesi yapılan çalışmaların yalnızca 4'ünde toplum 5.0 üzerine kavramsal bir inceleme gerçekleştirilmiştir. Kalan 12 literatür incelemesi toplum 5.0 kavramını belirli bir konu ile ilişkilendirerek açıklamaktadır.

Çalışmaların yalnızca 12'si araştırmalarının kapsamını belirli bir ülke ya da bölge ile sınırlandırmıştır. Çalışıldıkları ülkeler ve bölgeler açısından yayınların kapsamının çoğunlukla Japonya bağlamında incelendiği görülmektedir. Bununla birlikte, araştırma makaleleri içerisinde yer alan 11 yayından 10'u konuyu belirli bir ülke perspektifinden incelerken, 16 literatür incelemesinden yalnızca 2'si Japonya odaklı olarak konuyu tartışmaktadır. Bu iki makaleden biri enerji, diğeri insan kaynakları yönetimi perspektifinden toplum 5.0'1 ele almıştır.

Dergiler bağlamında elde edilen bulgular değerlendirildiğinde, çalışmaların yayınlandıkları dergilerin dağılımının genellikle birbirinden farklı olduğu görülmektedir. Yalnızca Computer dergisinde iki adet yayına rastlanmıştır.

Konular bağlamında bir değerlendirme yapıldığında, literatür incelemesi şeklinde tasarlanan çalışmalardan 4'ünün toplum 5.0 olgusunu sosyal boyutuyla, diğer bir deyişle söz konusu topluma mensup bireylerin taşıması gereken özellikler ve teknolojik gelişmelere adaptasyonları bağlamında inceledikleri görülmektedir. Bununla birlikte literatür incelemesi yapan çalışmaların 3 tanesinden biri insan güvenliği ve refahı, bir diğeri çevre ve ekoloji odağıyla sürdürülebilirlik perspektifinden toplumsal yaşam kategorisini desteklerken, kalan bir tanesi ise teknoloji bağımlılı̆̆ ekseninden toplumsal yaşama atıfta bulunmaktadır. Toplum kategorisine dahil edilebilecek son 3 çalışma ise, araştırma makalesi olup, bunlardan biri din ve etik, bir diğeri kuşak farklılıkları, sonuncusu akıllı şehir hususlarına eğilmektedir. İkinci bir kategori, çalışma yaşamı olarak ifade edilecek olursa, biri insan kaynakları yönetimi, biri takım çalışması, biri de stratejik planlama olmak üzere 3 çalışmanın yönetim olgusu, 2 çalışmanın turizm sektörü, 2 çalışmanın pazarlama, 1 çalışmanın ise maliyetleme bağlamında bu kategori ile ilişkili olduğu söylenebilmektedir. Geri kalan çalışmalar ise, teknoloji ve inovasyon kategorisinde yer almakta olup; bunlardan 6 tanesi doğrudan dijitalleşme konusu ile ilgili iken, 2 tanesi akı1lı teknolojileri sürdürülebilirlik ve enerji bakımından ele almakta, 1 tanesi ise bilim, teknoloji ve inovasyon ekosistemini açıklamaktadır. 
Akademik Yayınlar Işı̆̆ında Toplum 5.0 Kavramına İlişkin Bir Değerlendirme

Tablo 2: Toplum 5.0 Yazınındaki Ingilizce ve Türkçe Dilinde Yayınlanan Akademik Makaleler

\begin{tabular}{|c|c|c|c|c|c|c|c|}
\hline Sayı & Yil & Araştırmacı(lar) & Çalışmanın Adı & Dergi Adı & Kapsam & Konu & $\begin{array}{l}\text { Makale } \\
\text { Türü }\end{array}$ \\
\hline 1 & 2019 & Shiroishi vd. & $\begin{array}{l}\text { Better Actions for Society 5.0: } \\
\text { Using AI for Evidence-Based } \\
\text { Policy Making That Keeps } \\
\text { Humans in the Loop }\end{array}$ & Computer & - & Sürdürülebilirlik & $\begin{array}{l}\text { Literatür } \\
\text { İnceleme } \\
\text { (Review) }\end{array}$ \\
\hline 2 & 2019 & Fukuda & $\begin{array}{lr}\text { Science, } & \text { Technology } \\
\text { Innovation } & \text { and } \\
\text { Transformation toward Society } 5.0\end{array}$ & $\begin{array}{l}\text { International Journal of } \\
\text { Production Economics }\end{array}$ & $\begin{array}{l}\text { Amerika, } \\
\text { Japonya, } \\
\text { Almanya }\end{array}$ & $\begin{array}{l}\text { Bilim, Teknoloji ve } \\
\text { İnovasyon } \\
\text { Ekosistemi }\end{array}$ & $\begin{array}{l}\text { Araştırma } \\
\text { (Research) }\end{array}$ \\
\hline 3 & 2019 & Serpa ve Ferreira & $\begin{array}{l}\text { Society } 5.0 \text { and Sustainability } \\
\text { Digital Innovations: A Social } \\
\text { Process }\end{array}$ & $\begin{array}{l}\text { Journal of } \\
\text { Organizational Culture, } \\
\text { Communications and } \\
\text { Conflicts }\end{array}$ & - & $\begin{array}{l}\text { Sürdürülebilir Dijital } \\
\text { İnovasyon }\end{array}$ & $\begin{array}{l}\text { Araştırma } \\
\text { (Research) }\end{array}$ \\
\hline 4 & 2019 & Razak vd. & $\begin{array}{l}\text { Moving from Traditional to } \\
\text { Society 5.0: Case Study by Online } \\
\text { Transportation Business }\end{array}$ & $\begin{array}{l}\text { Journal of Distribution } \\
\text { Science }\end{array}$ & Endonezya & Pazarlama & $\begin{array}{l}\text { Araştırma } \\
\text { (Research) }\end{array}$ \\
\hline 5 & 2019 & Savaneviciene vd. & $\begin{array}{l}\text { Individual Innovativeness of } \\
\text { Different Generations in the } \\
\text { Context of the Forthcoming } \\
\text { Society } 5.0 \text { in Lithuania }\end{array}$ & $\begin{array}{l}\text { Inzinerine Ekonomika- } \\
\text { Engineering Economics }\end{array}$ & Litvanya & Kuşak Farklılıkları & $\begin{array}{l}\text { Araştırma } \\
\text { (Research) }\end{array}$ \\
\hline 6 & 2019 & Nieuwazny vd. & $\begin{array}{l}\text { How Religion and Morality } \\
\text { Correlate in Age of Society 5.0: } \\
\text { Statistical Analysis of Emotional } \\
\text { and Moral Associations with } \\
\text { Buddhist Religious Terms } \\
\text { Appearing on Japanese Blogs }\end{array}$ & $\begin{array}{l}\text { Cognitive Systems } \\
\text { Research }\end{array}$ & Japonya & Din ve Etik & $\begin{array}{l}\text { Araştırma } \\
\text { (Research) }\end{array}$ \\
\hline
\end{tabular}


Nisa AKIN - Evrim MAYATÜRK AKYOL - Olca SÜRGEVIL DALKILIÇ

\begin{tabular}{|c|c|c|c|c|c|c|c|}
\hline 7 & 2019 & Salimova vd. & $\begin{array}{l}\text { From Industry } 4.0 \text { to Society 5.0: } \\
\text { Challenges for Sustainable } \\
\text { Competitiveness of Russian } \\
\text { Industry }\end{array}$ & $\begin{array}{l}\text { IOP Conference Series: } \\
\text { Materials Science and } \\
\text { Engineering }\end{array}$ & Rusya & $\begin{array}{l}\text { Sürdürülebilir } \\
\text { Rekabet }\end{array}$ & $\begin{array}{l}\text { Araştırma } \\
\text { (Research) }\end{array}$ \\
\hline 8 & 2019 & Önday & $\begin{array}{l}\text { Japan's Society 5.0: } \text { Going } \\
\text { Beyond Industry } 4.0\end{array}$ & $\begin{array}{l}\text { Business and Economics } \\
\text { Journal }\end{array}$ & - & Kavramsal İnceleme & $\begin{array}{l}\text { Literatür } \\
\text { İnceleme } \\
\text { (Review) }\end{array}$ \\
\hline 9 & 2019 & Gladden & $\begin{array}{l}\text { Who Will Be the Members of } \\
\text { Society 5.0? Towards an } \\
\text { Anthropology of Technologically } \\
\text { Posthumanized Future Societies }\end{array}$ & Social Sciences & - & Kavramsal İnceleme & $\begin{array}{l}\text { Literatür } \\
\text { İnceleme } \\
\text { (Review) }\end{array}$ \\
\hline 10 & 2019 & Nurullin & $\begin{array}{llll}\text { Society } & 5.0: \text { a } & \text { Self-Devouring } \\
\text { System } & & & \end{array}$ & $\begin{array}{l}\text { International Journal of } \\
\text { Recent Technology and } \\
\text { Engineering (IJRTE) }\end{array}$ & - & Kavramsal İnceleme & $\begin{array}{l}\text { Literatür } \\
\text { İnceleme } \\
\text { (Review) }\end{array}$ \\
\hline 11 & 2019 & $\begin{array}{l}\text { Zaklasnik } \\
\text { Putnova }\end{array}$ & $\begin{array}{l}\text { Digital Society - Oppportunity or } \\
\text { Threat? Case Studies of Japan and } \\
\text { the Czech Republic }\end{array}$ & $\begin{array}{l}\text { Acta Universitatis } \\
\text { Agriculturae et } \\
\text { Silviculturae } \\
\text { Mendelianae Brunensis }\end{array}$ & $\begin{array}{l}\text { Çekya, } \\
\text { Japonya }\end{array}$ & Dijitalleşme & $\begin{array}{l}\text { Araştırma } \\
\text { (Research) }\end{array}$ \\
\hline 12 & 2019 & Şen & Dağıtık Kayıt Teknolojisi & Gümrük Ticaret Dergisi & - & $\begin{array}{ll}\text { Dijital } & \text { Kayit } \\
\text { Teknolojisi } & \end{array}$ & $\begin{array}{l}\text { Literatür } \\
\text { İnceleme } \\
\text { (Review) }\end{array}$ \\
\hline 13 & 2019 & Bahar vd. & $\begin{array}{l}\text { Akıllı Turizm ve Süper Akıllı } \\
\text { Turist Kavramları Ișıı̆ında } \\
\text { Geleceğin Turizm Rehberliğine } \\
\text { Bakış }\end{array}$ & $\begin{array}{l}\text { Journal of Travel and } \\
\text { Tourism Research }\end{array}$ & - & Turizm ve Turist 5.0 & $\begin{array}{l}\text { Literatür } \\
\text { İnceleme } \\
\text { (Review) }\end{array}$ \\
\hline 14 & 2019 & $\begin{array}{l}\text { Karabacak ve } \\
\text { Sezgin }\end{array}$ & $\begin{array}{l}\text { Türkiye'de Dijital Dönüşüm ve } \\
\text { Dijital Okuryazarlık }\end{array}$ & Türk İdare Dergisi & - & $\begin{array}{l}\text { Dijitalleşme, Dijital } \\
\text { Okuryazarlık ve } \\
\text { Eğitim }\end{array}$ & $\begin{array}{l}\text { Literatür } \\
\text { İnceleme } \\
\text { (Review) }\end{array}$ \\
\hline
\end{tabular}


Akademik Yayınlar Işı̆̆ında Toplum 5.0 Kavramına İlişkin Bir Değerlendirme

\begin{tabular}{|c|c|c|c|c|c|c|c|}
\hline 15 & 2018 & Shiroishi vd. & $\begin{array}{l}\text { Society 5.0: For Human Security } \\
\text { and Well-Being }\end{array}$ & Computer & - & Sürdürülebilirlik & $\begin{array}{l}\text { Literatür } \\
\text { İnceleme } \\
\text { (Review) }\end{array}$ \\
\hline 16 & 2018 & Riminucci & $\begin{array}{l}\text { Industry } 4.0 \text { and } \text { Human } \\
\text { Resources Development: A View } \\
\text { from Japan }\end{array}$ & $\begin{array}{l}\text { E-Journal of } \\
\text { International and } \\
\text { Comparative LABOUR } \\
\text { STUDIES }\end{array}$ & Japonya & $\begin{array}{l}\text { İnsan Kaynakları } \\
\text { Yönetimi }\end{array}$ & $\begin{array}{l}\text { Literatür } \\
\text { İnceleme } \\
\text { (Review) }\end{array}$ \\
\hline 17 & 2018 & Ahsan ve Murtaza & $\begin{array}{l}\text { The Human Role in Advanced } \\
\text { Manufacturing }\end{array}$ & $\begin{array}{l}\text { International Journal of } \\
\text { Mechanical and } \\
\text { Production Engineering } \\
\text { Research and } \\
\text { Development } \\
\text { (IJMPERD) }\end{array}$ & Hindistan & İnsan ve Takım & $\begin{array}{l}\text { Araştırma } \\
\text { (Research) }\end{array}$ \\
\hline 18 & 2018 & Bryndin & $\begin{array}{l}\text { System Synergetic Formation of } \\
\text { Society } 5.0 \text { for Development of } \\
\text { Vital Spaces on Basis of } \\
\text { Ecological Economic and Social } \\
\text { Programs }\end{array}$ & $\begin{array}{l}\text { Annals of Ecology and } \\
\text { Environmental Science }\end{array}$ & - & Çevre ve Ekoloji & $\begin{array}{l}\text { Literatür } \\
\text { İnceleme } \\
\text { (Review) }\end{array}$ \\
\hline 19 & 2018 & Ratti & $\begin{array}{lll}\text { Geographic } & \text { Knowledge } & - \\
\text { Paradigm of Society 5.0 } & \\
\end{array}$ & $\begin{array}{l}\text { Journal of Research and } \\
\text { Didactics in Geography }\end{array}$ & İtalya & Dijital Coğrafya & $\begin{array}{l}\text { Araştırma } \\
\text { (Research) }\end{array}$ \\
\hline 20 & 2018 & Frost ve Bauer & 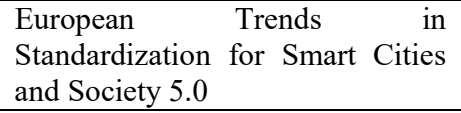 & NEC Technical Journal & $\begin{array}{l}\text { Avrupa } \\
\text { Birliği }\end{array}$ & Akıllı Şehirler & $\begin{array}{l}\text { Araştırma } \\
\text { (Research) }\end{array}$ \\
\hline 21 & 2018 & Takahashi & $\begin{array}{l}\text { Behavioral Economics of } \\
\text { Addiction in the Age of a Super } \\
\text { Smart Society: Society } 5.0\end{array}$ & $\begin{array}{l}\text { Oukan (Journal of } \\
\text { Transdisciplinary } \\
\text { Federation of Science } \\
\text { and Technology) } \\
\end{array}$ & - & Bağımlılık & $\begin{array}{l}\text { Literatür } \\
\text { Inceleme } \\
\text { (Review) }\end{array}$ \\
\hline
\end{tabular}


Nisa AKIN - Evrim MAYATÜRK AKYOL - Olca SÜRGEVIL DALKILIÇ

\begin{tabular}{|c|c|c|c|c|c|c|c|}
\hline 22 & 2018 & Fukuyama & $\begin{array}{l}\text { Society 5.0: Aiming for a New } \\
\text { Human-Centred Society }\end{array}$ & Japan SPOTLIGHT & - & Kavramsal İnceleme & $\begin{array}{l}\text { Literatür } \\
\text { İnceleme } \\
\text { (Review) }\end{array}$ \\
\hline 23 & 2018 & Okan Gökten & $\begin{array}{l}\text { Karanlıkta Üretim: Yeni Çağda } \\
\text { Maliyetin Kapsamı }\end{array}$ & $\begin{array}{l}\text { Muhasebe Bilim } \\
\text { Dünyası Dergisi }\end{array}$ & - & Maliyetleme & $\begin{array}{l}\text { Literatür } \\
\text { İnceleme } \\
\text { (Review) }\end{array}$ \\
\hline 24 & 2018 & Topsakal vd. & $\begin{array}{l}\text { Turizm } 4.0-\text { Turist } 5.0 \text { : İnsan } \\
\text { Devriminin Neden } \quad \text { Endüstri } \\
\text { Devrimlerinden Bir Numara Önde } \\
\text { Olduğuna İlişkin Bir Bakış }\end{array}$ & $\begin{array}{l}\text { Journal of Tourism } \\
\text { Intelligence and } \\
\text { Smartness }\end{array}$ & - & Turizm ve Turist 5.0 & $\begin{array}{l}\text { Literatür } \\
\text { Inceleme } \\
\text { (Review) }\end{array}$ \\
\hline 25 & 2017 & Sarif & $\begin{array}{l}\text { Society } 5.0 \text { Qalb with Tawhidic } \\
\text { Paradigm }\end{array}$ & $\begin{array}{l}\text { Journal of Education and } \\
\text { Social Sciences }\end{array}$ & Malezya & Stratejik Planlama & $\begin{array}{l}\text { Araştırma } \\
\text { (Research) }\end{array}$ \\
\hline 26 & 2017 & $\begin{array}{l}\text { Skobelev } \\
\text { Borovik }\end{array}$ & $\begin{array}{l}\text { On the Way from Industry } 4.0 \text { to } \\
\text { Industry 5.0: from Digital } \\
\text { Manufacturing to Digital Society }\end{array}$ & $\begin{array}{l}\text { International Scientific } \\
\text { Journal "Industry } 4.0 \text { " }\end{array}$ & - & Dijitalleşme & $\begin{array}{l}\text { Literatür } \\
\text { İnceleme } \\
\text { (Review) }\end{array}$ \\
\hline 27 & 2017 & Izui ve Koyama & $\begin{array}{l}\text { Future Energy and Electric Power } \\
\text { Systems and Smart Technologies }\end{array}$ & $\begin{array}{l}\text { IEEJ Transactions on } \\
\text { Electrical and Electronic } \\
\text { Engineering }\end{array}$ & Japonya & Enerji & $\begin{array}{l}\text { Literatür } \\
\text { İnceleme } \\
\text { (Review) }\end{array}$ \\
\hline
\end{tabular}




\section{Sonuç, Öneriler ve Kısıtlar}

Çalışma bulgularına göre, toplum 5.0 alanında yazılan akademik makalelerin yıllar bazında artış göstermesine karşın, kavramın henüz derinlikli bir akademik bakış açısına sahip olmadığı söylenebilmektedir. Bununla birlikte, Japonya'dan türetilen bir kavram olan toplum 5.0'ın Japon araştırmacıların yanı sıra Türk araştırmacılarca da incelenmiş olması umut vericidir. Ancak, çalışmaların kapsamları incelendiğinde, Türkiye üzerine yapılan bir çalışmanın mevcut olmadığı görülmektedir. Çalışma ile spesifik olarak Türkiye ile ilgili bir değerlendirme yapılmamakla birlikte, Türkiye evreninde toplum 5.0 kavramının analiz edilmesine duyulan ihtiyaç tespit edilmiştir.

Türkçe dilinde yazılan akademik makalelerin başlıklarında toplum 5.0'ın yer almaması da konu ile ilgili yerli yazın için bir eksiklik olarak düşünülebilmektedir. Çalışmada doğrudan toplum 5.0 olgusuna odaklanılması ve dolayısıyla da bu kavramın başlıkta yer almasının alan yazın taramalarında araştırmacılara katkı sağlayacağı düşünülmektedir.

Mevcut çalışmalarda toplum 5.0 konusunun turizm, dijitalleşme ve maliyetleme perspektifinden değerlendirilmesi de yerli yazında kavramsal tartışmalar olmaksızın belirli ilişkilendirmelerin yapıldığını ortaya koyabilmektedir. Ancak tüm yazın değerlendirildiğinde, toplum 5.0 kavramına ilişkin teorik incelemelerin yalnızca dört yayınla sınırlı kalması da, henüz yeni gelişen bir kavram için dikkat çekici bir bulgu olmuştur. Buna karşın geri kalan yayınlar kavramı belirli çalışma alanları perspektifinden değerlendirmişlerdir. Çalışma ile toplum 5.0 olgusu kavramsal perspektiften incelenerek, gerek kavramın çerçevesine ilişkin açıklamalar yapılmış gerekse birlikte ele alınan değişkenler ortaya konulmuştur. Bu bağlamda, henüz tanımlanması konusunda belirsizliklerin mevcut olduğu bu kavram ile ilgili çalışmak isteyen araştırmacılara başlangıç niteliğinde bir çerçeve oluşturulmaya çalışılmıştır.

Konu ile ilgili çalışan araştırmacılar ve kurumlarına ilişkin bulgular değerlendirildiğinde ise, araştırma, bilim ve teknoloji merkezlerinde çalışan araştırmacıların toplum 5.0 kavramı ile ilgili çalışıyor olması ve yanı sıra, üniversitelerin de teknoloji ve mühendislik alanlarında görev yapan araştırmacıların konuya ilgi göstermesi, sosyal bilimlerin alanına giren bir konunun teknik alanda çalışan araştırmacılarca ele alındığını ortaya koyması açısından önemlidir. Mühendislik ve teknoloji dergilerinin en az sosyal bilimler alanında yayımlanan dergiler kadar konu ile ilgili yayınlara yer vermesi de bu durumu desteklemektedir. Bununla birlikte, mühendislik ve teknoloji alanlarındaki dergilerde yayımlanan çalışmaların toplum 5.0'1 sosyal bilimler alanına giren konularla (sürdürülebilirlik, akıllı şehirler, insan, bağımlılık, din, etik ve rekabet) ilişkili olarak incelemesi de ayrıca dikkat çekmektedir. Bu doğrultuda, çalışma ile sosyal bilimler alanına giren toplum 5.0 olgusunun yine sosyal bilimler araştırmacıları tarafından ele alınması ve alanın akademik yayını olarak kurgulanması sağlanmıştır. 
Tüm bu tartışmalar, toplum 5.0'1n doğası ve felsefesi gereği bu konunun, sosyal bilimler alanında çalışan araştırmacılarca kavramsal olarak daha yaygın şekilde değerlendirilmesi gerekliliğini gösterebilmektedir. Ayrıca, toplum 5.0 kavramının ilişkili olduğu değişkenlerin ortaya konulması ile sosyal bilimcilerin ileride yapabilecekleri çalışmalarda hangi hususlara yoğunlaşacakları bir öneri olarak sunulabilmektedir. Bunun yanı sıra, araştırmanın temel kısıtının başlı̆̆ında ve anahtar sözcüklerinde toplum 5.0 ifadesi geçen makaleler ile sınırlı kalınması olduğu göz önünde bulundurulduğunda, konuya ilişkin raporlar gibi farklı türdeki yayınların da dâhil edilmesiyle yapılacak çalışmaların literatüre önemli katkılar sağlayacağı düşünülebilir. Gelecek çalışmalarda, kavramın tarihsel perspektiften değerlendirilmesi de toplum 5.0 olgusunu hazırlayan bağlamların neler olduğunun ortaya konulması açısından önem taşımaktadır. Yapılacak araştırmaların kurgulanmasında kavram kargaşalarının önüne geçilmesi, diğer bir deyişle toplum 5.0 olgusunu yansıtmayan ifadelerin kullanılmaması da alan yazının yanıltıcı olmaması adına kritik bir rol oynamaktadır. Bununla birlikte, kavramın farklı araştırma alanlarını etkileyen bir kapsamı olması itibariyle, disiplinler arası bir yaklaşımla incelenmesi konunun bütüncül bir bakış açısıyla değerlendirilmesi açısından önem taşımaktadır.

Literatüre ilişkin olanların yanı sıra, toplumsal düzeyde politika üretenlere yönelik öneriler de sunulabilmektedir. Bu noktada, toplum 1.0'dan toplum 5.0'a uzayan süreçte, yalnızca olumlu gelişmelerin değil, aynı zamanda bir takım zorlukların da ortaya çıkması önem kazanmaktadır. Her ne kadar toplum 5.0 endüstri 4.0 gibi teknik bir konu ile benzer anlama sahipmiş gibi değerlendirilse de, aslında endüstri 4.0'ın yarattı̆̆ teknolojik ortamda sosyal yaşamı iyileştirmek üzerine kurgulanmaktadır. Bu bağlamda, Japonya'nın da kavramı temellendirdiği teknolojik çevrede yaşlı nüfusa yönelik çözümler üretilmesi, doğal çevrenin sürdürülebilir kılınması, sağlık ve eğitim gibi temel alanlarda iyileştirmeler yapılması, genel anlamda teknoloji ile toplumsal yapının uyumlaştırılması hususlarında geliştirilecek politikaların gelecek dönemler için ciddi bir katma değer yaratacağı düşünülmektedir.

\section{Kaynaklar}

Ahsan, R. \& Murtaza, M. A. (2018). The human role in advanced manufacturing. International Journal of Mechanical and Production Engineering Research and Development (IJMPERD), 8(6), 255-262.

Bahar, M. \& Topsakal, Y. (2019). Akıllı turizm ve süper akıllı turist kavramları 1şı̆̆ında geleceğin turizm rehberliğine bakış. Journal of Travel and Tourism Research, 14, 72-93.

Bryndin, E. (2018). System synergectic formation of society 5.0 for development of vital spaces on basis of ecological economic and social programs. Annals of Ecology and Environmental Science, 2(4), 12-19.

Frost, L. \& Bauer, M. (2018). European trends in standardization for smart cities and society 5.0. NEC Technical Journal, 13(1), 58-63. 
Akademik Yayınlar Işı̆̆ında Toplum 5.0 Kavramına İlişkin Bir Değerlendirme

Fukuda, K. (2019). Science, technology and innovation ecosystem transformation toward society 5.0. International Journal of Production Economics, https://doi.org/10.1016/j.ijpe.2019.07.033.

Fukuyama, M. (2018). Society 5.0: Aiming for a new human-centered society. https://www.jef.or.jp/journal/ July/August, 47-50.

Gladden, M. E. (2019). Who will be the members of society 5.0? Towards an anthropology of technologically posthumanized future societies. Social Sciences, 8(148), 1-39.

Izui, Y. \& Koyama, M. (2017). Future energy and electric power systems and smart technologies. IEEJ Transactions on Electrical and Electronic Engineering, 12, 453-464.

Karabacak, Z. İ. \& Sezgin, A. A. (2019). Türkiye'de dijital dönüşüm ve dijital okuryazarlık. Türk İdare Dergisi, 91(488), 319-343.

Nieuwazny, J. vd. (2019). How religion and morality correlate in age of society 5.0: Statistical anlysis of emotional and moral associations with Buddhist religious terms appearing on Japanese blogs. Cognitive Systems Research, https://doi.org/10.1016/j.cogsys.2019.09.026.

Nurillin, R. A. (2019). Society 5.0: A self-devouring system. International Journal of Recent Technology and Engineering (IJRTE), 8(2), 4001-4004.

Okan Gökten, P. (2018). Karanlıkta üretim: Yeniçağda maliyetin kapsamı. Muhasebe Bilim Dünyası Dergisi, 20(4), 880-897.

Önday, Ö. (2019). Japan's society 5.0 - going beyond industry 4.0. Business and Economics Journal, 10(2), 1-6.

Ratti, B. (2018). Geographic knowledge: Paradigm of society 5.0. Journal of Research and Didactics in Geography, 1(7), 123-126.

Razak, M. vd. (2019). Moving from traditional to society 5.0: Case study by online transportation business. Journal of Distribution Science, 17(9), 93102.

Riminucci, M. (2018). Industry 4.0 and human resources development: A view from Japan. E-Journal of International and Comparative Labour Studies, 7(1), 1-17.

Salimova, T. vd. (2019). From industry 4.0 to society 5.0: Challenges for sustainable competitiveness of Russian industry. IOP Conf. Series: Materials Science and Engineering 497, https://doi.org/10.1088/1757899X/497/1/012090.

Saracel, N. \& Aksoy, I. (2020). Toplum 5.0: Süper Ak1llı Toplum. Social Sciences Research Journal, 9(2): 26-34.

Sarif, S. M. (2017). Society 5.0 qalb with tawhidic paradigm. Journal of Education and Social Sciences, 8(1): 208-217.

Savaneviciene, A. vd. (2019). Individual innovativeness of different generations in the context of the forthcoming society 5.0 in Lithuania. Inzinerine Ekonomika-Engineering Economics, 30(2), 211-222. 
Serpa, S. \& Ferreira, C. M. (2019). Society 5.0 and sustainability digital innovations: A social process. Journal of Organizational Culture, Communications and Conflicts, 23(1), 1-14.

Shiroishi, Y., Uchiyama, K. \& Suzuki, N. (2018). Society 5.0: For human security and well-being. IEEE Computer Society, November, 73-78.

Shiroishi, Y., Uchiyama, K. \& Suzuki, N. (2019). Better actions for society 5.0: Using all for evidence-based policy making that keeps humans in the loop. IEEE Computer Society, July, 91-95.

Skobelev, P. O. \& Borovik, S. Y. (2017). On the way from industry 4.0 to industry 5.0: From digital manufacturing to digital society. International Scientific Journal, 2(6), 307-311.

Şen, F. (2019). Dağıtık kayıt teknolojisi. Gümrük Ticaret Dergisi, 17, 85-94.

Takahashi, T. (2018). Behavioral economics of addiction in the age of a super smart society: Society 5.0. Oukan, 12(2), 119-122.

Topsakal, Y., Yüzbaşıŏlu, N., Çelik, P., \& Bahar, M. (2018). Turizm 4.0 - Turist 5.0: İnsan devriminin neden endüstri devrimlerinden bir numara önde olduğuna ilişkin bakış. Journal of Tourism Intelligence and Smartness, 1(2), 1-11.

Tübitak (2016). Yeni Sanayi Devrimi, Akıllı Üretim Sistemleri, Teknoloji Yol Haritası. Tübitak Bilim Teknoloji ve Yenilik Politikaları Daire Başkanlığı.

Wang, F., Yuan, Y., Wang, X. \& Qin, R. (2018). Societies 5.0: A new paradigm for computational social systems research. IEEE Transactions on Computational Social Systems, 5(1), 2-8.

Zaklasnik, M. \& Putnova, A. (2019). Digital society-opportunity or threat? Case studies of Japan and Czech Republic. Acta Universitatis Agriculturae et Silviculturae Mendelianae Brunensis, Mendel University Press, 67(4), 1085-1095. 